\title{
Diagnosis of Hypophosphatasia
}

\author{
Cleiton Fantin ${ }^{1}$, Denise Correa Benzaquem ${ }^{1}$ and Vânia Mesquita Gadelha Prazeres ${ }^{2}$ \\ 1. Laboratório de Citogenética, Universidade do Estado do Amazonas, Manaus 69065-001, Brasil \\ 2. Departamento de Saúde Materno Infantil, Universidade Federal do Amazonas, Manaus 69076-005, Brasil
}

\begin{abstract}
Objective: HPP (Hypophosphatasia) is a congenital disease characterized by a deficiency of tissue-specific ALP (alkaline phosphatase), which causes the generation of abnormal bone and tooth tissue. The clinical manifestations are variable, from neonatal forms with high mortality to milder adult forms with fractures and osteomalacia. The present study reports a clinical case of HPP, with emphasis on the physical characteristics and laboratory tests. The patient was attended at the medical genetics outpatient clinic of the Association of Parents and Friends of the Exceptional of Manaus (Associação de Pais e Amigos dos Excepcionais-APAE/Manaus). Methodology: For the case report, anamnesis, peripheral blood G-band karyotyping, Vitamin and ALP dosage and resonance examination were performed. Results: A.M.M.S, 9 years, non-consanguineous parents, no bone disease in the family, with one sister from the mother. Birth weight AGA without intercurrence. The patient presented a slight delay in psycho-motor development and was diagnosed with craniostenosis through CNS imaging examination. The physical examination, in addition to a short stature, showed dolichocephaly, frontal bossing, curved tibias and great dental compromise with many early cavities and loss of teeth. Laboratory evaluation: ALP dosage: 63/L ( $N=69-325)$; Vitamin B6 dosage: 27.4 (5.2-34.1). The mother and the younger sister also had an ALP result below that expected for the age. Conclusions: The clinical phenotype and laboratory diagnosis of the patient were compatible with ICD Q78 HPP.
\end{abstract}

Key words: HPP, ALP, child.

\section{Introduction}

HPP (Hypophosphatasia) is a genetic congenital disease, described by Rathbun in 1948 [1]. It is characterized by low serum ALP (alkaline phosphatase) activity due to loss of function mutations within the gene for the tissue-specific ALP isoenzyme, resulting in decompensation in bone and tooth mineralization [2, 3]. This enzyme is widely distributed in the body, in adults it comes partly from the liver (thermostable fraction) and partly from bones, and from the reticuloendothelial and vascular systems (thermolabile fraction) generating genetically different isoenzymes with similar catalytic properties, which are encoded at independent loci [4]. In children, under normal conditions it reaches its highest activity in the growth phase, as $85 \%$ of this isoenzyme is located in the osteoblasts (related to calcification and formation of bone structures) and 15\% in the liver [5]. Exposure to

Corresponding author: Cleiton Fantin, Ph.D., professor, research fields: genetics and cytogenetics. variation in ALP levels may be physiological, as observed in gestation occurring at the end of the first trimester of the pregnancy, reaching peak levels (approximately twice the normal values) [6], or genetic when there are mutations in the tissue-nonspecific ALP gene. The gene is found on chromosome $1 \mathrm{p} 36.1$, which is composed of 12 exons distributed over more than 50 $\mathrm{kb}$ and has high allelic heterogeneity with more than 330 different mutations, mostly nonsense, already known [7-9]. Depending on the degree of the mutation and whether it is homozygous or heterozygous it can result in more severe phenotypes and even lethality [10].

Clinical manifestations are variable, from neonatal forms with high mortality due to complications in the skeletal structure that impairs respiration, to milder adult forms with fractures and osteomalacia. These manifestations can include irregular ossification, bone demineralization, short stature, bone pain and early tooth loss [6, 11]. In children, clinical symptoms may appear within the first 6 months of life, with the patient 
presenting no phenotype indicative of the disease after the birth. One of the first observed symptoms is respiratory complications due to rachitic deformities of the thorax. Despite the presence of an open fontanelle, premature craniosynostosis is a common finding that can lead to increased intracranial pressure. In all the pediatric forms of HPP, the risk of craniosynostosis should always be considered, with a period of neurological monitoring, including ophthalmoscopy being recommended until adolescence [12].

The diagnosis can be made, even during intrauterine life, through radiographic examinations along with a positive family history, which can lead to better treatment and be applied as early as the first day of life, thus increasing the possibility of mitigating the clinical manifestations of the disease [13-15]. If the diagnosis is not made at this stage, it can be done through biochemical analysis based on the determination of serum ALP levels and increase in phosphoethanolamine, pyridoxal-5'-phosphate and inorganic pyrophosphate in the serum or urine. However, in these cases treatment may have limited results. In addition, for the patients with late diagnosis, parathyroid hormone administration is performed in adult HPP and enzyme replacement therapy with a soluble recombinant human ALP in the most severe clinical cases [16, 17].

The conventional diagnosis can also be confirmed by genetic testing [8]. To establish the definitive diagnosis, sequencing of the ALPL gene is essential to confirm HPP when biochemical and clinical data are not sufficiently clear or in a prenatal assessment of severe HPP in couples with an affected child or pregnancy $[8,18]$.

\section{Case Report}

For the case report, anamnesis, peripheral blood G-band karyotyping, vitamin and ALP dosage and resonance examination were performed. A.M.M.S, male, 9, non-consanguineous parents, negative for bone disease history in the family, with one sister from the mother. Pregnancy without intercurrences, labor dystocia, full-term. The birth weight was appropriate for the gestational age (between the 10th and 90th percentiles) without intercurrence, however, the mother reported the first hospitalization of the child at 15 days of age due to seizure, with treatment until 3 years of age. The mother reported several hospitalizations due to respiratory infection. The patient presented a slight delay in psycho-motor development and was diagnosed with craniostenosis through central nervous system imaging examination. He evolved with short stature and underwent hormonal replacement with pediatric endocrinologist monitoring. The physical examination, in addition to a short stature, showed dolichocephaly, frontal bossing, curved tibias and great dental compromise with many early cavities and loss of teeth. Laboratory evaluation: Peripheral blood G-band karyotyping showed 46, XX (normal); skull resonance: craniostenosis, calcification impairment pale globes and subcortical white matter; ALP dosage: 63/L ( $N=69-325)$; Vitamin B6 dosage: 27.4 (5.2-34.1). The mother and the younger sister also presented an ALP result below that expected for the age. The clinical and laboratory data presented here were obtained respecting the confidentiality of the information according to the assumptions that regulate research ethics. She started treatment with alpha asphalt 6 months ago, indicated to decrease bone pain. After initiation of the treatment, a fracture of the forearm was reported, with no improvements in the other conditions.

\section{Discussion}

HPP is a disease with broad clinical features, with forms ranging from mild to lethal. We present a case with clinical features characteristic of childhood HPP. It is important to highlight the differential diagnosis and its diagnostic difficulty. The prognosis for patients with childhood HPP is uncertain, however, clinical and skeletal deterioration indicates a lethal course. Currently, there is no curative treatment available for 
HPP. Therefore, the treatment seeks to improve the symptoms and clinical features, especially in relation to pain, seizures and other metabolic phenomena, e.g., nephro calcification [8]. Patients with HPP do not have sufficient non-specific tissue ALP functioning in their normal range, which leads to weak bones. However, clinical trials using asfotase alfa have demonstrated a progressive improvement in bone mineralization with a consequent improvement in respiration and even the abandonment of mechanical ventilation. Asfotase alfa is a modified copy of the human ALP enzyme and serves as a replacement for the defective enzyme, increasing functional ALP levels [11, 13, 15, 19].

The HPP triage begins with the investigation of levels of ALP and Vitamin B6, with decreased enzyme levels and increased Vitamin B6 levels constituting a good marker for HPP. However, in the present case high levels of vitamin B6 were not observed, although a decrease in ALP was confirmed in both the patient and in other members of the family.

There were also reports of a history of hospitalization of the patient due to respiratory infection. It has been reported that thoracic cage deformity leads to frequent respiratory problems and is closely related to the death of children born with HPP, with fatality usually occurring within the first 6 months of life [20]. The physical examination presented many characteristic symptoms of the disease, such as short stature, dolichocephaly, frontal bossing, curved tibias and great dental compromise with many early cavities and loss of teeth. The clinical signs and symptoms of HPP in children are very heterogeneous in their presentation, severity and course. Bone abnormalities (impaired bone mineralization, leg deformation, pain, rickets, abnormal growth) and dental abnormalities (premature loss of deciduous teeth) are best known [21].

\section{Conclusions}

The physical examination of the patient associated with biochemical and genetic tests demonstrated the characteristic decrease in ALP activity and the radiological findings were compatible with the HPP disease. HPP is a rare and underdiagnosed disease. Presenting cases that show their clinical and laboratory evolution may help in the recognition of these patients.

\section{Conflict of Interest}

The authors report no conflict of interest.

\section{References}

[1] Rathbun, J. C. 1948. "Hypophosphatasia: A New Developmental Anomaly.” Am. J. Dis. Child. 75: 822-31.

[2] Whyte, M. P. 2013. "Hypophosphatasia." In Genetics of Bone Biology and Skeletal Disease, edited by Thakker, R. V., Whyte, M. P., Eisman, J., and Igarashi, T. Academic Press, 337-60.

[3] Gurevich, E., and Landau, D. 2017. "Severe Infantile Hypophosphatasia.” Harefuah 156 (1): 27-8.

[4] Bellido, M. C., Barrios, J. M. T., Guisado, N. P., and de Cos, S. R. 2003. "Hiperfosfatasemia asintomática no familiar persistente. Comentarios a una observación.” Vox Paediatrica 11 (1): 19-21.

[5] Pace, A. E., and Osinde, M. E. 1999. "Hiperfosfatasemia transitória benigna de la infância. Uma aproximación diagnóstica racional.” Arch Argent Pediatr 97: 383-90.

[6] Aacosta-aragón, M. A., Rodríguez-Vélez, G. H., and Mena-gallego, J. 2016. “Hipofosfatasia.” Revista Colombiana Salud Libre 11 (supl): 98-101.

[7] Mornet, E., Hofmann, C., Bloch-Zupan, A., Girschick, H., and Le Merrer, M. 2014. "Clinical Utility Gene Card for: Hypophosphatasia.” Eur. J. Hum Genet 22 (4).

[8] Mornet, E. 2008. "Hypophosphatasia." Best Pract Res Clin Rheumatol 22 (1): 113-27.

[9] Whyte, M. P. 2010. "Physiological Role of Alkaline Phosphatase Explored in Hypophosphatasia." Ann NY Acad Sci. 1192: 190-200.

[10] Bishop, N., Munns, C. F., and Ozono, K. 2016. “Transformative Therapy in Hypophosphatasia.” Arch Dis Child June 101 (6): 514-5.

[11] Matos, E. N., Neto, S. M., Jesus, L. G., Modesto, A. E. D., Queiroz, G. M. S. 2017. "Hipofosfatasia com apresentação na infância: relato de caso.” Rev. Bras. de Reumatologia 57 (S1): S323-S324.

[12] Martos-Moreno, G. A., et al. 2017. "Hipofosfatasia: Manifestaciones clínicas, recomendaciones diagnósticas y opciones terapêuticas.” An Pediatr.

[13] Taketani, T., Onigata, K., Kobayashi, H., Mushimoto, Y., Fukuda, S., and Yamaguchi, S. 2014. "Clinical and Genetic Aspects of Hypophosphatasia in Japanese Patients.” Arch Dis Child 99: 211-5.

[14] Okazaki1, Y., Kitajima, H., Mochizuki, N., Kitaoka, T., 
Michigami, T., and Ozono, K. 2016. "Lethal Hypophosphatasia Successfully Treated with Enzyme.” Replacement from Day 1 after Birth. Eur. J. Pediatr 175: 433-7.

[15] Takahashi, S. H., Murotsuki, J., Satoh, S., Yamada, T., Hayakawa, H., Kouduma, Y., Masakatsu, S., Atsushi, W., Osamau, M., and Gen, N. 2017. "Parental Serum Alkaline Phosphatase Activity as an Auxiliary Tool for Prenatal Diagnosis of Hypophosphatasia.” Prenatal Diagnosis 37 (5): 491-6.

[16] Mornet, E., and Nunes, M. E. 2007. "Hypophosphatasia." Orphanet J. Rare Dis. 2: 40.

[17] Orimo, H. 2010. "The Mechanism of Mineralization and the Role of Alkaline Phosphatase in Health and Disease.” J. Nippon Med. Sch. 77: 4-12.
[18] Silva, I., Castelao, W., Mateus, M., and Branco, J. C. 2012. "Childhood Hypophosphatasia with Myopathy: Clinical Report with Recent Update.” Acta Reumatol Port 37: 92-6.

[19] Whyte, M. P. 2016. "Hypophosphatasia Aetiology, Nosology, Pathogenesis, Diagnosis and Treatment.” Nat. Rev. Endocrinol 12: 233-46.

[20] Ceballo, E. L., Pérez, M. E. D., and Nunez, R. A. 2001. "Hipofosfatasia. Presentation de um caso." Ver. Cubana Ortop Traulatol 15 (1): 87-9.

[21] Rothenbuhler, A., and Linglart, A. 2017. "Hypophosphatasia in Children and Adolescents: Clinical Features and Treatment. (Hypophosphatasie chez l'enfant et l'adolescent: présentation clinique et traitement.)" Archives de Pédiatrie 24 (5S2): 5S66-5S70. 